\title{
Experimental studies concerning stressed rocks resistance to disintegration
}

\author{
Leonid Shmatovskyi ${ }^{1, *}$ \\ ${ }^{1}$ Institute of Geotechnical Mechanics named by N. Poljakov of National Academy of Sciences of \\ Ukraine, 49005, Dnipro, Simferopolska Str., 2a, Ukraine
}

\begin{abstract}
The paper represents both methods and results of experiments concerning stressed rocks impact in their resistance (i.e. contact strength) to disintegration. The experimental dependence of the indicator of contact strength of rocks on the degree of stress concentration in the conditions of slaughter production is established.
\end{abstract}

\section{Introduction}

Only mine environment can give the most reliable experimental results of stressed rocks impact on their resistance (i.e. contact strength) to disintegration. However, impossibility to obtain such wide-range data restricts full-scale studies. Hence, laboratory simulation of stressed rocks state is widely used in practice.

\section{Methods}

We apply special facility as well as a tool to measure strength while carrying out laboratory studies concerning stress rocks resistance to disintegration.

Rock sample load with the use of the mentioned facility can be comparable with analytical model has been described in [1] where stope rocks of a mine working are considered as a limited, restrained isotropic layer with $h_{0}$ thickness; the layer is effected by concentrated loads.

According to a scheme demonstrated in Figure 1, stresses within a rock sample with $d_{0}$ diameter along the whole layer height $h_{0}$ are calculated according to formula:

$$
\sigma=\frac{P}{S}
$$

where $P$ are forces acting on the sample, $H$ and $S$ is lateral face along which the sample is compacted, $\mathrm{m}^{2}$.

Taking into consideration dimensions of elements of the compacting device (Fig. 1) as well as the rock sample, stresses within the latter are:

\footnotetext{
*Corresponding author: haritonroots@gmail.com
} 


$$
\sigma=\frac{\pi d_{n} h_{n}\left(P-P_{0}\right)}{\pi d_{0} h_{0}}=\frac{d_{n}}{d_{0}} \frac{h_{n}}{h_{0}} \Delta P,
$$

where $\sigma$ are stresses within the analyzed layer of the rock sample, $\mathrm{Pa} ; d_{n}$ is diameter of the compacting device power part, $\mathrm{m} ; d_{0}$ is diameter of the rock sample, $\mathrm{m} ; h_{n}$ is working space of the compacting device, $\mathrm{m} ; h_{0}$ is height of the sample stress layer, $\mathrm{m} ; \Delta P$ is pressure transmitted to $h_{0}$ layer of the sample, Pa.

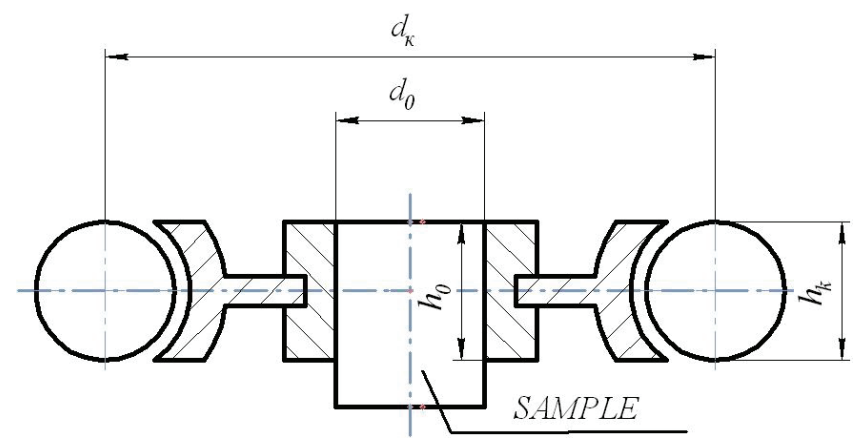

Fig. 1. Analytical model to calculate stress within the rock sample layer.

A tool to measure strength is applied to determine contact strength within the stressed layer of rock samples. A gauge controls pressure within hydraulic system of the tool to measure strength. Content of the analysis is to force an intender sample into a free surface of the stressed layer. The intender is in the form of a flattened cone with a point angle 1.05 rad. It has a flat foundation with $2-5 \mathrm{~mm}$ diameter; its area is $7-20 \mathrm{~mm}^{2}$. Forcing of the intender takes one step until a hole intend is formed each time at a new surface of the sample. Both gauge and indicator record a moment of brittle rock failure.

In terms of the known basal area of the intender and measured forces of rock failure under it, contact strength is determined using the formula:

$$
P_{c}^{\prime}=\frac{\sum_{1}^{n} P_{1}}{n S_{1}}
$$

where $P_{c}{ }^{\prime}$ is contact strength of the stressed layer of the rock sample, $\mathrm{Pa} / \mathrm{mm}^{2} ; P_{1}$ is a load during the brittle failure (i.e. hole intend), $\mathrm{Pa} ; n$ is the number of experiments to determine contact strength; and $S_{1}$ is intender area, $\mathrm{mm}^{2}$.

The required number of experiments $\mathrm{n}$ is determined statically while taking into consideration coefficient of variation $K_{v a r}$. The standard formula of mathematical statistics has been used as a calculating one:

$$
n=\frac{K_{v a r}}{K_{d o p}} \cdot t^{2},
$$

where $t$ and $K_{d o p}$ are reliability and reasonable error respectively.

\section{Results and their discussions}

The analysis results concerning significant experimental amount to determine contact strength of rocks [2], have shown that average-weight values of the coefficients of variation 
achieve $23 \%$. In this context, the required number of experiments for the majority of brittle rocks, including sandstones, is $6-10$ when reliability is 0.95 and reasonable error is 10 $15 \%$. If the above is taken into consideration, then to determine contact strength, the number of experiments in terms of each preset stress value within a rock sample may be specified as eight.

To carry out laboratory experiments, sandstone samples were taken in the form of sandstone cores with $96 \mathrm{~mm}$ diameter. Strength coefficients of the sandstones were $f=6-8$, and compression strength was $\sigma_{s t}=(600-800) \cdot 10^{5} \mathrm{~Pa}$.

Experimentally, sample load is performed according to the data from Table 1.

Table 1. Stresses and stress coefficients in the rock samples.

\begin{tabular}{|l|c|c|c|c|c|}
\hline $\begin{array}{l}\text { Stresses within the preset layer of } \\
\text { rock samples } \sigma, \mathrm{Pa}\end{array}$ & 0 & $160 \cdot 10^{5}$ & $320 \cdot 10^{5}$ & $430 \cdot 10^{5}$ & $640 \cdot 10^{5}$ \\
\hline Stress coefficient $k$ & 0 & 0.2 & 0.4 & 0.6 & 0.8 \\
\hline
\end{tabular}

The experimental data, concerning contact strength determination, were processed in accordance with a procedure to determine rock characteristics [2], and foundations of mathematical statistics [3]. Reliability of the experimental results and coefficient of the experimental variation [2] are 93-96\% and 8-13\% respectively. The obtained values of coefficient of variation and reliability of the results, concerning determination of contact strength indices, show that their values are within permissible limits.

Figure 2 demonstrates analytical dependence of the contact strength index upon concentration degree of natural stresses.

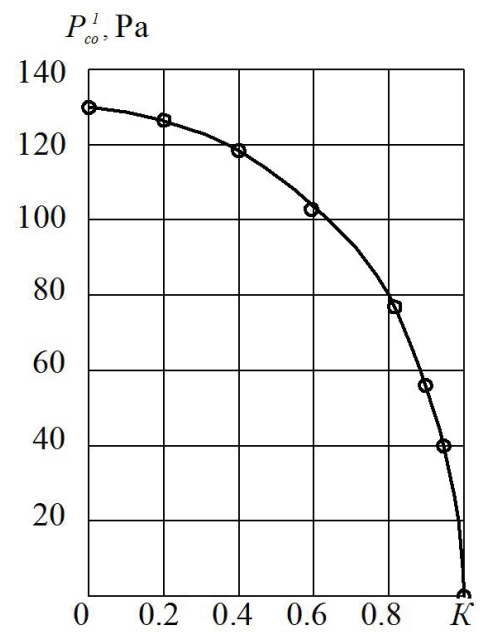

Fig. 2. Analytical dependence of contact strength index on the concentration degree of natural stresses.

Using processing results of the experimental data dependence, shown in Figure 3, has been plotted. The dependence demonstrates a degree of stress effect on the rock resistance indices $P_{c}$ ' disintegration. Like in Figure 2, contact strength of unstressed sandstone $P_{c o}{ }^{\prime}=130 \mathrm{~Pa}$ has been taken as initial index $P_{c o}$.

Comparative analysis of data, listed in Figures 2 and 3, explains that nature of analytical dependence and experimental dependence of $P_{c}{ }^{\prime}$ indices of rock stress degree are identical. When stresses are more than $70 \%$ of sandstone strength limits, even minor intender action on the sandstone results in its failure followed by intensive crack. 


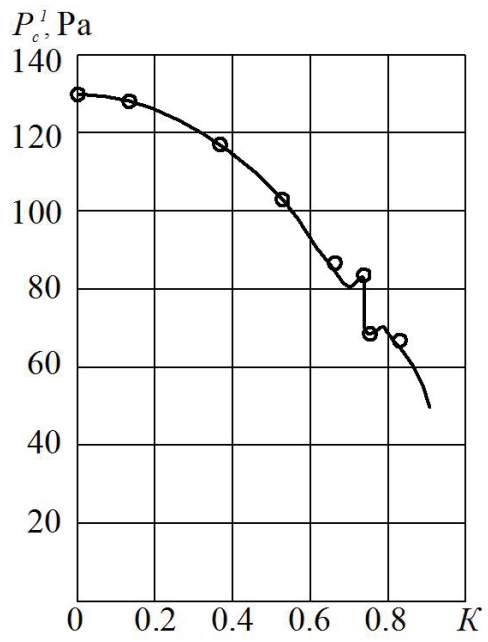

Fig. 3. Experimental dependence of contact strength index on the stress concentration.

Similar dependences have been obtained in terms of other brittle rocks (i.e. quartzite's, granites). Figure 4 shows their generalized characteristic. Comparison of experimental data with analytical one constitutes a match; divergence is not more than $\pm 10 \%$. Thus, dependence (3) may be recommended to solve practical problems intended to calculate a process of rock disintegration using mechanical tools.

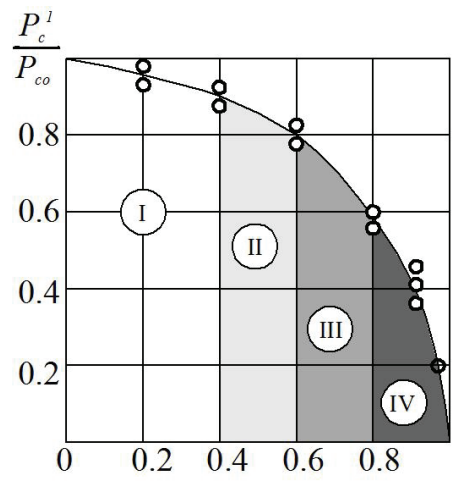

Fig. 4. Generalized characteristic of contact strength of brittle rocks depending upon their stress degree.

Practices of mine working construction within the stressed rocks [1, 4] confirm the fact that stope rocks of a mine working can experience various stress actions which also determines resistance value of the rock to failure. Figure 4 demonstrates degree of natural stress rock effect on their resistance to failure. In this context, it is possible to separate following areas:

I area - when 0-0.4 variation of $k$ coefficient means minor effect of natural stresses on rock resistance to failure since variation of $P_{c}$ indices is $8 \%$ only to compare with similar indices if stresses are not available;

II area - 0.4-0.6 variation of $k$ coefficient means that rock resistance to failure within the area decreases by $20 \%$ to compare with the state when stresses are not available. Rocks, belonging to the area, are being considered as average stressed ones;

III area - increase in $k$ coefficient up to 0.8 results in almost $50 \%$ decrease in $P_{c}$ ' values to compare with corresponding indices of rocks being free of stresses. Such rock state 
should be considered as high stressed one; and

IV areas - when $k$ values are more than 0.8 , rock resistance to failure drops sharply. Rock state within the area is ultimate one; self-destruction will take place if $k=1$.

\section{Conclusions}

The data, concerning qualitative variation and quantitative variation of indices of rock resistance to destruction may be applied while determining $P_{c}$ ' effect on operation modes of effectors of coal shearers in the process of the mine working construction within the stressed rocks. To do that, it is required to analyze contact strength indices in terms of a mine working stope area.

\section{References}

1. Zorin, A.N. (1978). Upravlenie dinamicheskimi proyavleniyami gornogo davleniya. Moskva: Nedra

2. Baron, L.I., Glatman, L.B. (1966). Kontaktnaya prochnost gornykh porod. Moskva: Nedra

3. Pustylnik, E.I. (1968). Statisticheskie metody analiza i obrabotki nablyudeniy. Moskva: Nauka

4. Nikolin, V.I., Meliksetov, S.S., Berkovich, I.M. (1967). Vybrosy porody i gaza. Moskva: Nedra 